\title{
Hydrodehalogenation of Polychlorinated Aromatic Halides by Hypophosphite with Pd/C Catalyst under Multiphase Conditions
}

\author{
Carlos Alberto Marques, Maurizio Selva and Pietro Tundo* \\ Dipartimento di Scienze Ambientali, Università di Venezia, Ca' Foscari, Calle Larga Santa Marta, 2137- \\ 30123, Venice, Italy
}

\begin{abstract}
Polyhalogenated benzenes in the presence of a $\mathrm{Pd} / \mathrm{C}$ catalyst with sodium hypophosphite in a multiphase system consisting of a hydrocarbon solvent, concentrated aqueous alkali and a quaternary onium salt undergo reduction with rapid and progressive displacement of all their chlorine atoms. The onium salt, being insoluble in both the organic and the aqueous phases, coats, as a third liquid phase, the $\mathrm{Pd} / \mathrm{C}$ catalyst. The strong alkaline medium and the phase-transfer agent are synergic. Operating at $50^{\circ} \mathrm{C}, 1,2,4,5$-tetrachlorobenzene gives after $2.5 \mathrm{~h}$ a $99 \%$ yield of benzene.

Enhancement of the reaction rate, compared with already known methods, has been attributed to the transfer of phosphite anion from the aqueous solution to the catalyst surface, to partition of halogenated compounds between the hydrocarbon solution and the liquid phase of the phasetransfer agent and to the rapid removal of $\mathrm{HCl}$ adsorbed on $\mathrm{Pd} / \mathrm{C}$ by the alkaline medium.

The reaction is also effective with aryl bromides and deactivated $p$-methoxyaryl halides.
\end{abstract}

Hydrodehalogenation of aromatic halides, especially chlorides, is of interest because it allows transformation of potential pollutants of the environment into their corresponding aromatic hydrocarbons without production of waste. Such reactions may also have synthetic potential, where regioselective dehalogenation of polyhalogenated benzenes could afford compounds difficult to synthesise directly. Further, where chlorination of benzene (or toluene) produces considerable amounts of polychlorobenzenes (or polychlorotoluenes), because of the comparable rate constants of the related consecutive reactions, reactions of these polychloro compounds under the conditions described may produce the desired lesshalogenated compounds.

Our initial study of the palladium-catalyzed hydrodehalogenation of polychlorobenzenes was aimed at improving the reduction rate by developing new reaction conditions. Use of a classic reduction catalyst such as palladium on carbon $(\mathrm{Pd} / \mathrm{C})$ gave, as reported herein, reduction of tri- and tetra-chlorobenzenes to less chlorinated compounds and to benzene. This problem is of interest because four chlorine atoms have to be removed at once.

Chlorobenzene can be reduced to benzene by a variety of methods: ${ }^{1 \mathrm{a}-\mathrm{b}}$ hydrodehalogenation with supported palladium catalysts, ${ }^{2 a} \mathrm{Pd} / \mathrm{C},{ }^{2 b}$ platinum catalysts on spinel, ${ }^{3}$ and reactive aluminium powders. ${ }^{4}$

Hypophosphite has also been reported as a hydrogen source, ${ }^{5 a . b}$ the same compound has also been used also for the hydrogenation of functionalized organic compounds, ${ }^{5 d, e}$ for the hydrogenolysis of phenolic bonds, ${ }^{5 f}$ and aliphatic $\mathrm{CBr}, \mathrm{CCl}$ bonds, ${ }^{5 g}\left[\mathrm{Et}_{3} \mathrm{NH}\right]\left[\mathrm{H}_{2} \mathrm{PO}_{2}\right]$ has been used for the reduction of nitro derivatives and carbonyl compounds. ${ }^{\text {sh }}$

Formate salts have also been described as hydrogen donors although in the reactions reported, high temperatures, high pressures, or long reaction times are involved. In particular, Sasson and co-workers ${ }^{6}$ have recently reported an efficient reduction system for monochlorobenzenes that employs formate salts and $\mathrm{Pd} / \mathrm{C}$ as a catalyst. The reaction is performed in one phase (methanol or ethanol and water) in which both the inorganic salts and the aromatic halides are dissolved.

We have used two immiscible phases, organic and aqueous: the organic one consists of an inert aliphatic or aromatic hydrocarbon. The use of an aprotic organic phase was also required because 1,2,4,5-tetrachlorobenzene (TeCB) is scarcely soluble in methanol.

\section{Results}

Hydrodehalogenation of TeCB gives at first 1,2,4-trichlorobenzene (TCB) and then, in order: the three dichlorobenzene isomers (DCB), chlorobenzene and benzene (Scheme 1). If this

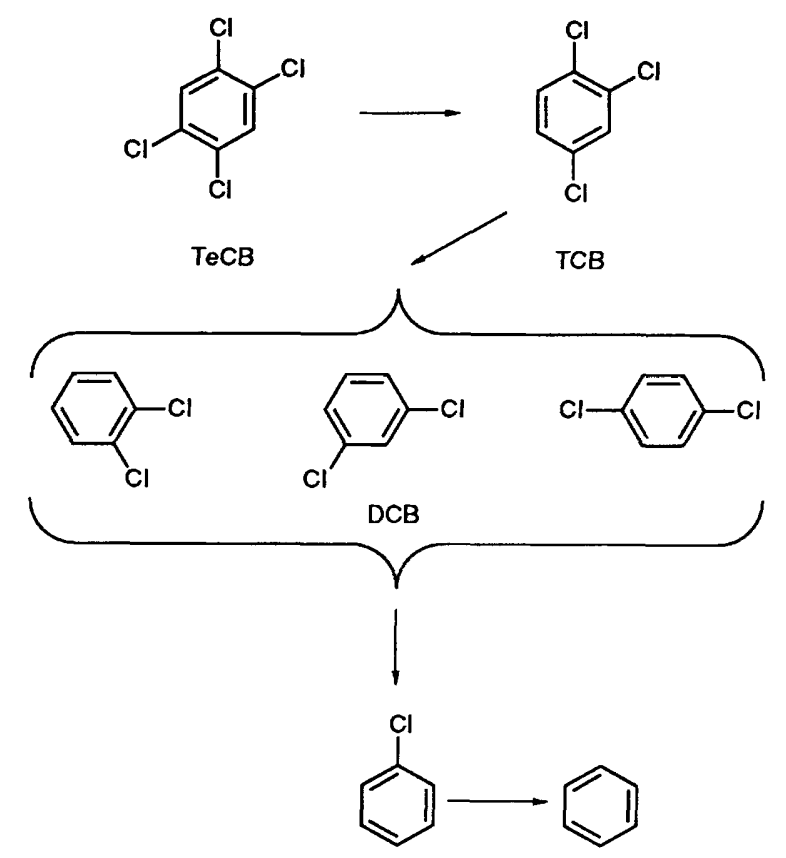

Scheme 1

reaction is carried out in the presence of a large amount of catalyst, as in previously reported methods, ${ }^{7 a-b}$ the rate increases considerably and the reduction to benzene was effective even in absence of the hydrogen source. $\uparrow$ This high activity is probably due to hydrogen already present on the carbon support. In effect, the catalyst is used as a reagent.

Since TeCB is sparingly soluble in methanol, it was not

$\dagger$ In a large excess of catalyst $(\mathrm{Pd} / \mathrm{Cl}=0.4)$ according to ref. 7 , the reduction of $\mathrm{TeCB}$ was very fast. Operating at $50^{\circ} \mathrm{C}$, with a solution of TeCB in isooctane $\left(0.07 \mathrm{~mol} \mathrm{dm}^{-3} ; 15 \mathrm{~cm}^{3}, 1.05 \mathrm{mmol}\right), \mathrm{HCONH}_{4}(0.63$ $\mathrm{g}, 10 \mathrm{mmol}) \mathrm{MeOH}\left(2.5 \mathrm{~cm}^{3}\right)$ as a solvent and $\mathrm{Pd} / \mathrm{C}(5 \% ; 0.128 \mathrm{~g}), 100 \%$ conversion was obtained after only $8 \mathrm{~min}$. 
Table 1 Hydrodehalogenation of 1,2,3,4-tetrachlorobenzene (TeCB) with $\mathrm{Pd} / \mathrm{C}$ catalyst and $\mathrm{H}_{2} \mathrm{PO}_{2}{ }^{-}$as a hydrogen source. Comparison between different multiphase systems ${ }^{a}$

\begin{tabular}{|c|c|c|c|c|c|c|}
\hline Entry & Solvent & Aqueous phase & Source of hydrogen & PT agent ${ }^{b}$ & $t / \mathrm{h}$ & $\%$ Conversion \\
\hline 1 & Isooct $-\mathrm{H}_{2} \mathrm{O}$ & - & $\mathrm{NaH}_{2} \mathrm{PO}_{2}$ & 1 & 3.0 & 0 \\
\hline 2 & Isooct-EtOH & - & $\mathrm{HCO}_{2} \mathrm{NH}_{4}$ & - & 4.0 & 29 \\
\hline 3 & Isooct-EtOH & $\mathrm{K}_{2} \mathrm{CO}_{3}(56 \%)$ & $\mathrm{NaH}_{2} \mathrm{PO}_{2}$ & - & 4.0 & 34 \\
\hline 4 & Isooct & $\mathrm{KOH}(50 \%)$ & $\mathrm{NaH}_{2} \mathrm{PO}_{2}$ & 2 & 2.0 & 100 \\
\hline 5 & Isooct-MeOH & $\mathrm{KOH}(50 \%)$ & $\mathrm{NaH}_{2} \mathrm{PO}_{2}$ & 1 & 3.0 & 0 \\
\hline 6 & Isooct & - & $\mathrm{HCO}_{2} \mathrm{NH}_{4}$ & 3 & 3.0 & 16 \\
\hline 7 & $\mathrm{MeOH}^{c}$ & $\mathrm{KOH}(50 \%)$ & $\mathrm{NaH}_{2} \mathrm{PO}_{4}$ & 1 & 1.5 & $100^{d}$ \\
\hline
\end{tabular}

For all the following Tables and Figures, conversion refers to the disappearance of the reagent (TeCB in this case). Yield means the conversion into a given product.

${ }^{a}$ For the reaction conditions see Experimental Section: $T=50^{\circ} \mathrm{C} ; \mathrm{TeCB}: \mathrm{Pd}: \mathrm{NaH}_{2} \mathrm{PO}_{2} \cdot \mathrm{H}_{2} \mathrm{O}: \mathrm{PT}$ agent $=1.0: 0.03: 2.8: 0.4$ (mol:mol), respectively; $n$-dodecane was used as internal standard. Isooctane, $7.0 \mathrm{~cm}^{3}$ (entries 1-6); ethanol, $4.0 \mathrm{~cm}^{3}$ (entries 2 and 3 ), methanol, $4.0 \mathrm{~cm}^{3}$ (entry 5 ); $50 \%$ aq. $\mathrm{KOH}, 4.0 \mathrm{~cm}^{3}$ (entries 4 and 5); $56 \%$ aq. $\mathrm{K}_{2} \mathrm{CO}_{3}, 4.0 \mathrm{~cm}^{3}$ (entry 3). ${ }^{b}$ PT agents 1,2 or $3 .{ }^{c}$ TeCB in methanol $\left(0.01 \mathrm{~mol} \mathrm{dm}^{-3} ; 7.0 \mathrm{~cm}^{3}\right) .{ }^{d} \mathrm{TeCB}^{-}$ reacts completely; in spite of the presence of $\mathrm{H}_{2}$ in the reaction mixture, no reduction products are present.

Table 2 Influence of amount of catalyst $(5 \% \mathrm{Pd} / \mathrm{C})$ on the hydrodechlorination of $\mathrm{TeCB}$, performed in isooctane and aq. $\mathrm{KOH}$ $50 \%{ }^{a}$

\begin{tabular}{llllllll}
\hline & & & \multicolumn{2}{l}{$\%$ Yield } \\
\cline { 5 - 7 } Entry & $\begin{array}{l}\text { Pd/TeCB } \\
(\mathrm{mol} / \mathrm{mol})\end{array}$ & $\begin{array}{c}\% \\
\text { after } 2.0 \mathrm{~h}\end{array}$ & TCB & DCBB & $\mathrm{PhCl}$ & Benzene \\
\hline 1 & 0.01 & 36 & 28 & 8 & - & - \\
2 & 0.03 & 59 & 42 & 10 & 1 & - \\
3 & 0.05 & 64 & 26 & 11 & 1 & 22 \\
4 & 0.20 & 99 & - & - & - & 98 \\
\hline
\end{tabular}

${ }^{a}$ Reaction conditions are those of Table 1, entry 4; the PT agent was [n$\left.\mathrm{C}_{16} \mathrm{H}_{33} \mathrm{PBu}\right]_{3} \mathrm{Br} .{ }^{b} o / p$ ratio $=4 ; m$-dichlorobenzene, trace amount

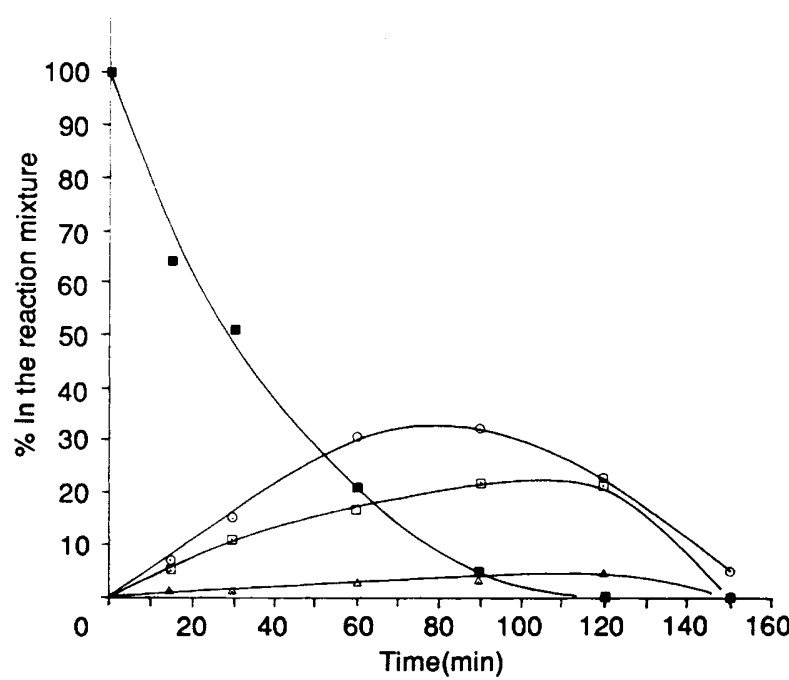

Fig. 1 Hydrodehalogenation of $\mathrm{TeCB}$ with sodium hypophosphite. $\%$ TeCB; $\mathrm{O} \% \mathrm{TCB} ; \square \% \mathrm{DCB}$ (ortho- and para-isomers); $\triangle \% \mathrm{PhCl}$. Yield in benzene is not shown. Conditions were those of Table 1, entry 4 .

possible to make a close comparison of its dehalogenation rate with other aryl chlorides under the conditions reported. ${ }^{6}$

However, since TeCB is soluble in isooctane, a $0.07 \mathrm{~mol} \mathrm{dm}^{-3}$ solution could be prepared and its hydrodehalogenation assayed in the presence of an immiscible methanolic phase with hypophosphite as the hydrogen source. Moreover, with isooctane as the solvent and in the absence of methanol, use of a phase-transfer (PT) catalyst allowed observation of the transfer of hypophosphite anion, under solid-liquid PTcatalysis conditions. ${ }^{8}$ In both cases the reaction rate was very slow (see Table 1). However, in aqueous $\mathrm{KOH}$, and in the presence of a PT agent, 1-3, the reaction rate was fast (entry 4).

$$
\begin{aligned}
& \left(\mathrm{C}_{8} \mathrm{H}_{17}\right)_{3} \mathrm{~N}^{+} \mathrm{CH}_{3} \mathrm{Cl}^{-} \quad \mathrm{C}_{16} \mathrm{H}_{33} \mathrm{P}^{+}(\mathrm{Bu})_{3} \mathrm{Br}^{-} \\
& \text {Aliquat } 336
\end{aligned}
$$$$
1
$$

The PT agent, being insoluble both in the organic and the aqueous phase, covers the insoluble $\mathrm{Pd} / \mathrm{C}$ as a liquid film. In fact, it constitutes a third liquid phase which, during the reaction, its density being intermediate to the other two, lies between them. Moreover, under such multiphasic conditions (Table 1), $\mathrm{NaH}_{2} \mathrm{PO}_{2}$ is superior to formate anion as a hydrogen source for hydrodehalogenations.

No reaction occurs in the absence of $\mathrm{Pd} / \mathrm{C}$ (Table 2), product yields increasing with the amount of catalyst used; however, the observed rate increase is not directly proportional to the amount of catalyst used.

In the presence of $50 \%$ aqueous $\mathrm{KOH}$ and Aliquat 336 as a PT agent, partial dechlorination of TeCB is complete after $2 \mathrm{~h}$, with near quantitative conversion into benzene* (Fig. 1) after $2.5 \mathrm{~h}$; the reaction proceeds through all the low chlorinated intermediates (see Scheme 1). For comparison, the reaction was performed under the same conditions as described in Fig. 1, but promoted by $\mathrm{NaH}_{2} \mathrm{PO}_{2} \cdot \mathrm{H}_{2} \mathrm{O}, \mathrm{HCO}_{2} \mathrm{Na}$ and $\mathrm{HCO}_{2} \mathrm{NH}_{4}$, both in the presence and in the absence of a PT catalyst (Fig. 2). In these cases, in order to provide constant hydrogen generation, $\mathrm{NaH}_{2} \mathrm{PO}_{2} \cdot \mathrm{H}_{2} \mathrm{O}(0.2 \mathrm{~g})$ was added every $30 \mathrm{~min}$. When the hydrodehalogenation is insufficiently fast the reaction may stop, since the decomposition of hypophosphite effected by palladium is faster, thus causing cessation of hydrogen formation.

The results of Fig. 2 show that the reaction is faster in the presence of a PT agent, its rate being comparable with and higher than the most active catalysts previously reported. ${ }^{9}$

In a preliminary investigation of the reaction mechanism, the influence of different factors affecting the reaction were studied.

Table 3 reports the results for reactions carried out in a variety of solvents (isooctane, cyclohexane and benzene) in the presence of $50 \%$ aqueous $\mathrm{KOH}$; a methanol-isooctane mixture

* Compared to the internal standard, mass balance of benzene was $<100 \%$, maybe because the former is more volatile and, therefore, easily lost by evaporation. 


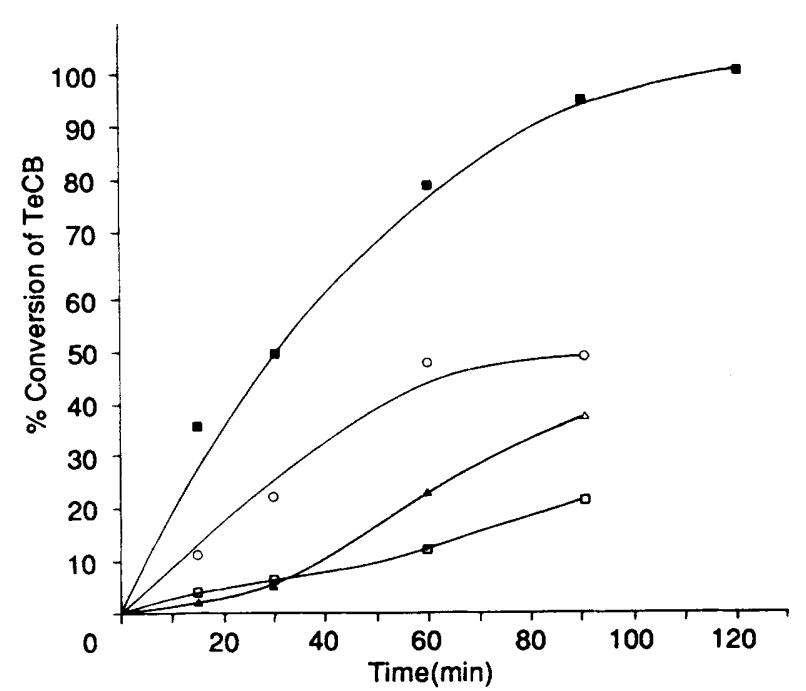

Fig. 2 Comparison between different hydrogen sources in hydrodehalogenation of TeCB. Conversion of TeCB according to Scheme 1; the PT agent is also reported: $\mathrm{NaH}_{2} \mathrm{PO}_{2}$ with 1; $\bigcirc \mathrm{NaH}_{2} \mathrm{PO}_{2}$ without PT agent; $\triangle \mathrm{HCO}_{2} \mathrm{NH}_{4}$ with $1 ; \square \mathrm{HCO}_{2} \mathrm{Na}$ with 1 . Conditions were those of Table 1 , entry 4 .

Table 3 Influence of solvent in the hydrodehalogenation of TeCB.*

\begin{tabular}{lllllll}
\hline & & & \multicolumn{5}{c}{$\%$ Yield } \\
\cline { 5 - 7 } Entry & Solvent & $t / h$ & $\%$ Conversion & TCB & DCB & PhCl \\
\hline 1 & Cyclohexane & 3.0 & 90 & 10 & 13 & 2 \\
2 & Benzene & 3.3 & 98 & 18 & $42^{a}$ & 12 \\
3 & Isooctane & 2.3 & 100 & - & 5 & - \\
\hline
\end{tabular}

* For conditions, see of Table 1, entry 4.

${ }^{a} o / p$ ratio $=7 ; m$-dichlorobenzene, trace amount

was also employed. In the latter case, there were two liquid phases with the insoluble $\mathrm{Pd} / \mathrm{C}$ catalyst. The highest rate was achieved in the apolar isooctane although benzene was also an effective solvent under these conditions. It is interesting to observe that in benzene the reaction does not rapidly proceed to complete reduction, some selectivity in mono- and dihalogenated products being observed.

The role of aqueous $\mathrm{KOH}$ on the reaction was investigated in order to discover whether its effect was to provide an alkaline environment (which removes the hydrochloric acid produced by the reaction), or if some other physical phenomenon (e.g. density or viscosity) might be involved. Thus, reactions were carried out in which the $\mathrm{KOH}$ concentration was varied and in which saturated aqueous solutions of inorganic salts $(\mathrm{NaCl}$, $\mathrm{KBr}, \mathrm{Na}_{3} \mathrm{PO}_{4}$ and $\mathrm{K}_{2} \mathrm{CO}_{3}$ ) were used (see in Table 4). As shown, high reaction rates were possible only at high $\mathrm{KOH}$ concentrations; other salts had no effect on the reaction.

The synergistic activation effect of $\mathrm{KOH}$ and PT catalyst is reported in Fig. 3. As shown, the PT agent and 50\% aqueous $\mathrm{KOH}$ substantially increase the reaction rate. In the presence of these reagents, $\mathrm{TeCB}$ was no longer present after $120 \mathrm{~min}$, while in their absence the reaction was only $20 \%$ complete after 150 min.

Also the nature of the PT agent affects the reaction rate. The results recorded in Table 5 demonstrate that hydrodechlorination of TeCB is influenced by quaternary salt lipophilicity, since the less lipophilic pyridinium salt ${ }^{3}$ fails to promote the reaction, the reaction rate being lower in its presence. In fact, this onium salt is soluble in the aqueous phase, so that a third liquid phase is absent in this case.

Further, at high concentrations of $\mathrm{KOH}$, no nucleophilic
Table 4 Influence of $\mathrm{KOH}$ concentration and of different saturated inorganic solutions on the hydrodehalogenation of TeCB.*

\begin{tabular}{llrr}
\hline Entry & Aqueous phase & $t / \mathrm{h}$ & $\%$ Conversion \\
\hline 1 & $\mathrm{KOH}, 20 \%$ aq. & 2.0 & 74 \\
2 & $\mathrm{KOH}, 30 \%$ aq. & 2.0 & 83 \\
3 & $\mathrm{KOH}, 50 \%$ aq. & 2.0 & 100 \\
4 & $\mathrm{KOH}, 75 \%$ aq. & 1.3 & 100 \\
5 & $\mathrm{NaCl}, 35 \%$ aq. & 2.0 & 7 \\
6 & $\mathrm{KBr}, 45 \%$ aq. & 1.0 & 7 \\
7 & $\mathrm{~K}_{2} \mathrm{CO}_{3}, 60 \%$ aq. & 1.3 & 21 \\
8 & $\mathrm{Na}_{3} \mathrm{PO}_{4}, 56 \%$ aq. & 1.3 & 27
\end{tabular}

* For the reaction conditions, see Table 1 , entry 4 . In all cases the aqueous phase was $4.0 \mathrm{~cm}^{3}$

substitution products (i.e. 2,4,5-trichlorophenol) were detected, the reaction yielding completely dehalogenated compounds.* This result might be attributable to the high rate of hydrodehalogenation and the low temperature. As a result, the $\mathrm{PT}$ agent, which coats the $\mathrm{Pd} / \mathrm{C}$ catalyst, transfers $\mathrm{H}_{2} \mathrm{PO}_{2}{ }^{-}$ anion from the aqueous phase. In this way, by mediating its decomposition on $\mathrm{Pd} / \mathrm{C}$, it allows hydrogen to be present where the reaction actually occurs.

The results for a competitive reaction carried out on the four mono-halogenated benzenes are reported in Fig. 4, benzene being the sole product. The observed reaction rates well correlate with those mostly reported in the literature.

In our case, the reactivity scale of mono-halogenated benzenes is $\mathrm{PhI}>\mathrm{PhBr}>\mathrm{PhCl} \gg \mathrm{PhF}$. These results contrast with those of Sasson ${ }^{6}$ who reports $\mathrm{PhCl}>\mathrm{PhBr}>\mathrm{PhI} \gg \mathrm{PhF}$.

Table 6 records results for hydrodechlorination reactions using as the reagents the products that, according to Scheme 1 , are progressively formed in the reduction of TeCB; that is, TCB, DCB (ortho- and para-) and $\mathrm{PhCl}$. These results indicate that, in the presence of isooctane, less chlorinated benzenes are more reactive. However, as in the reaction of $\mathrm{TeCB}$, it was not possible to clarify the kinetic order of the reaction, because induction periods and the composite heterogeneous system do not offer consistent data.

The reaction is effective also with the less-activated paramethoxy-halogenated benzenes, both chloro- and bromoderivatives easily yielding anisole (Table 7 ). The reactivities of para-chloroanisole, para-bromoanisole, chlorobenzene and bromobenzene are comparable, but the $p$-methoxy-substituted compounds are slightly less reactive.

\section{Discussion}

Under the reaction conditions described in this paper, hypophosphite was a more reactive hydrogen source than formate; the decomposition rate of hypophosphite compared to formate does not account for this since sodium formate was decomposed by $\mathrm{Pd} / \mathrm{C}$ to hydrogen at the same rate as hypophosphite.

The other noteworthy feature of the reaction reported here is the promoting presence of PT agents (Figs. 2 and 3 and Table 5), which mediates anionic exchange with the aqueous solution (the proper function of a PT catalyst) and the sorption of the compound to be dehalogenated from the hydrocarbon solution on its third liquid phase. In spite of the complex exchange and partition phenomena, the reactions performed in the presence of a PT agent were faster than in its absence.

* Chloride analysis carried out by the Volhard method on the aqueous phase of the reaction mixture of entry 4 of Table 1 , showed that 2.2 mmol of $\mathrm{Cl}^{-}$were present, corresponding to the complete removal of all four chlorine atoms from the $\mathrm{TeCB}$ reagent. 


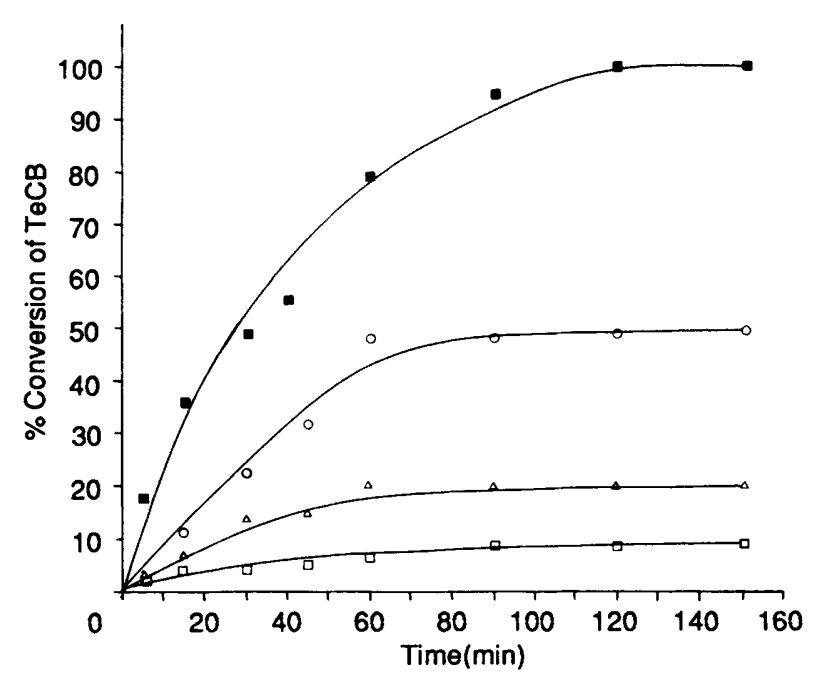

Fig. 3 Effect of $\mathrm{KOH}$ and PT agent on the hydrodehalogenation of TeCB carried out in a two-phase system by $\mathrm{Pd} / \mathrm{C}$ catalyst and sodium hypophosphite: with $\mathrm{KOH}$ and $1 ; \triangle$ with $\mathrm{H}_{2} \mathrm{O}$ and $\mathrm{1} ; \mathrm{O}$ without PT agent and with $\mathrm{KOH} ; \square$ without $\mathrm{KOH}$ and 1 . Conditions were those of Table 1, entry 4

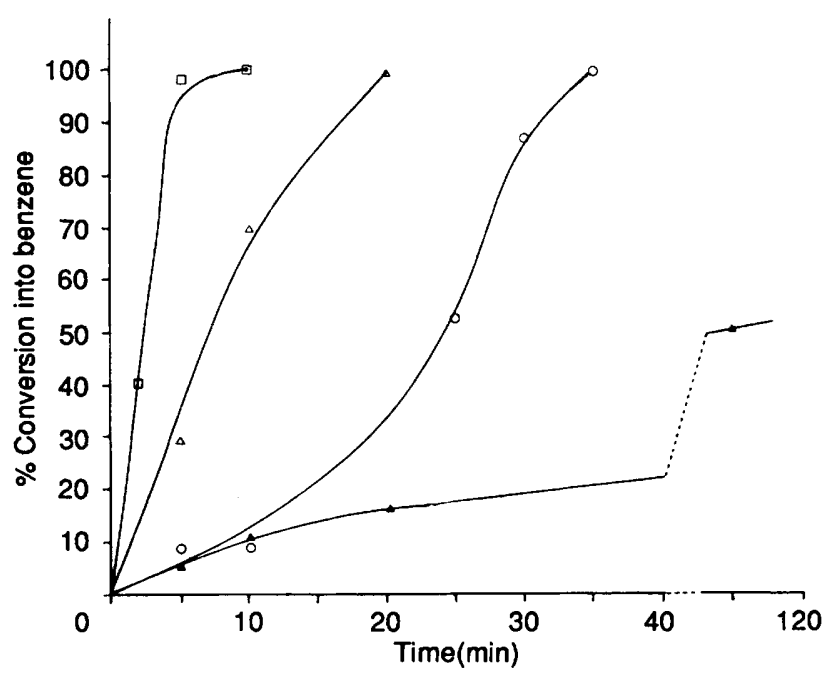

Fig. 4 Competitive hydrodehalogenation reaction on $\mathrm{PhF}, \mathrm{PhCl}$, PhBr, PhI: $\square=\mathrm{I} ; \Delta=\mathrm{Br} ; \mathrm{O}=\mathrm{Cl} ; \Delta=\mathrm{F}$. See Experimental section for details. Reaction conditions were those of Table 1, entry 4.

Factors that Affect the Reaction.-The observed non-linear relationship between reaction rate and the amount of catalyst may depend either on sorption phenomena (which may occlude catalyst centres), on a not-proportional distribution of PT agent over the surface of carbon, or on other factors.

As shown in Fig. 3, both the presence of a PT agent and concentrated aqueous $\mathrm{KOH}$ are necessary in order to enhance substantially the reaction rate. However, not all the onium salts are effective (Table 5), only those which are insoluble in both phases promoting the reaction. The importance of having a liquid film of a polar and non-protic nature (as the bulky quaternary onium salts 1 and 2 are), which is coated on the carbon surface may be responsible for the increased reaction rate. However, a quaternary onium salt improves the reaction rate only in the case of aryl chlorides, since aryl bromides showed the opposite effect (Table 7). The reason for such different behaviour is not clear at present.

The solvent markedly affects the completeness of the reaction: the apolar solvent strongly improves the hydrodehalogenation reaction (Table 1). The reasons for such behaviour are not clearly evident. Exchange phenomena between the solvent and the liquid PT agent and/or formation of unusual interfaces between
Table 5 Effects of the nature of PT agent on the hydrodehalogenation of $\mathrm{TeCB}$ carried out in a biphasic system with a $\mathrm{Pd} / \mathrm{C}$ catalyst and sodium hypophosphite*

\begin{tabular}{llll}
\hline Entry & PT agent & $t / h$ & $\%$ Conversion \\
\hline 1 & 1 & 2.3 & 100 \\
2 & 2 & 3.0 & 62 \\
3 & 3 & 3.0 & 35 \\
4 & No PT agent & 3.0 & 49 \\
\hline
\end{tabular}

* For reaction conditions, see Table 1 , entry 4.

Table $6 \%$ Decrease of the reagent versus time in the hydrodehalogenation of TeCB, TCB, 1,2- and 1,4-DCB and $\mathrm{PhCl}$ *

\begin{tabular}{llrlll}
\hline & \multicolumn{5}{c}{ Time (min) } \\
\cline { 3 - 6 } Entry & Reagent & 5 & 15 & 30 & 60 \\
\hline 1 & TeCB $^{a}$ & - & 36 & 49 & $79^{b}$ \\
2 & TCB & 11 & 67 & 80 & $96^{c}$ \\
3 & $p-\mathrm{DCB}$ & 9 & 60 & 86 & $96^{d}$ \\
4 & $o-\mathrm{DCB}$ & 6 & 24 & 73 & $100^{e}$ \\
5 & PhCl & 13 & 50 & 98 & $100^{s}$ \\
\hline
\end{tabular}

* Reaction conditions were those of Table 1, entry 4. Reaction products of TCB and DCBs were benzenes progressively dechlorinated.

${ }^{a}$ This result was also reported in Table 1, entry $4 .{ }^{b}$ After $2.30 \mathrm{~h}, 95 \%$ of benzene (compared to the internal standard). ${ }^{c}$ After $1.15 \mathrm{~h}, 98 \%$ of benzene. ${ }^{d}$ After $1.0 \mathrm{~h}, 89 \%$ of benzene. ${ }^{e}$ After $55 \mathrm{~min}, 87 \%$ of benzene. ${ }^{f}$ After $45 \mathrm{~min}, 100 \%$ conversion; benzene, $99 \%$ yield.

Table $7 \%$ Decrease of reagent versus time in some dehalogenations

\begin{tabular}{llrrr}
\hline & & \multicolumn{3}{c}{ Time (min) } \\
\cline { 3 - 5 } Entry & Reagent & 5 & 10 & 20 \\
\hline 1 & Chlorobenzene $^{a}$ & 13 & 22 & $97^{c}$ \\
2 & p-Chloroanisole $^{b}$ & 7 & 15 & 90 \\
3 & Bromobenzene $^{a}$ & 37 & 79 & 100 \\
4 & $p$-Bromoanisole $^{b}$ & 35 & 67 & 100 \\
\hline
\end{tabular}

Reaction conditions were those of Table 1, entry 4.

${ }^{a}$ Reaction product: benzene. ${ }^{b}$ Reaction product: anisole. ${ }^{c}$ See Table 6 , entry 5 .

the different phases may be responsible for the observed selectivity toward dichlorobenzenes in the hydrodehalogenation of TeCB carried out in benzene solvent. This is the reverse of that observed when different chlorinated benzenes are allowed to react in isooctane (Table 6).

However, the mutual reactivity of the four mono-halogenated benzenes is not modified under such conditions. As shown in Fig. 4, $\mathrm{PhCl}, \mathrm{PhBr}, \mathrm{PhI}$ and $\mathrm{PhF}$ follow the order usually reported in the literature for the hydrogenation reactions. ${ }^{10}$

It has been reported that hydrodehalogenation of chlorobenzene by $\mathrm{Pd} / \mathrm{C}$ proceeds toward the dissociative absorption of the molecule on the surface which is followed by the addition of hydrogen. ${ }^{11}$ This mechanistic explanation may require that interphase phenomena are important. Moreover, it may explain the considerable effect of $\mathrm{KOH}$. The $\mathrm{HCl}$ produced, adsorbed on the surface, is quickly removed by strong alkaline media, so allowing a faster regeneration of the catalyst surface. With such an interpretation the PT agent may have its promoting role in wetting the carbon surface, simultaneously transferring alkaline anions from the aqueous phase to the insoluble catalyst.

Conclusions.-The conditions here reported for hydrodehalogenation are characterized by a high reaction rate. Such high activity of the Pd catalyst may open the way to new 
applications. A possible industrial use might be that after the electrophilic chlorination of benzene, polyhalogenated byproducts are converted into less chlorinated benzenes in benzene solvent; this would allow the next chlorination to be carried out without production of any waste.

\section{Experimental}

Materials.-All reagents were commercially available and were used without further purification. $5 \% \mathrm{Pd} / \mathrm{C}$ was by Fluka (Art. No. 75992).

Apparatus.-The reactions were carried out in a Erlenmeyer flask $\left(20 \mathrm{~cm}^{3}\right)$, thermostatted at $50 \pm 0.1^{\circ} \mathrm{C}$, and at atmospheric presure. The reaction mixtures were magnetically stirred at a constant rate $(\mathrm{ca} .1000 \mathrm{rpm})$ in the presence of an internal standard (n-dodecane) and were analysed by gaschromatography.

Reduction of 1,2,4,5-Tetrachlorobenzene (Tables 1, 2, 3, 4, 5 and Figs. 1, 2, 3).-In an Erlenmeyer flask $\left(20 \mathrm{~cm}^{3}\right)$ equipped with a condenser and thermostatted at $50^{\circ} \mathrm{C}\left( \pm 0.1^{\circ} \mathrm{C}\right)$, a solution of TeCB in isooctane $\left(0.07 \mathrm{~mol} \mathrm{dm} \mathrm{dm}^{-3} ; 7.0 \mathrm{~cm}^{3}, 0.5\right.$ mmol) containing $\mathrm{n}$-dodecane as internal standard, $50 \%$ aqueous $\mathrm{KOH}\left(4 \mathrm{~cm}^{3}\right), 5 \% \mathrm{Pd} / \mathrm{C}(0.032 \mathrm{~g}, 0.15 \mathrm{mmol}$ of $\mathrm{Pd})$ and Aliquat $336(0.085 \mathrm{~g}, 0.20 \mathrm{mmol})$ were magnetically stirred at $c a$. $1000 \mathrm{rpm} ; \mathrm{NaH}_{2} \mathrm{PO}_{2} \cdot \mathrm{H}_{2} \mathrm{O}(0.20 \mathrm{~g}, 1.9 \mathrm{mmol})$ was added every $30 \mathrm{~min}$.

In the experiments performed with formate salts as hydrogen sources, sodium formate $(0.20 \mathrm{~g})$ or ammonium formate $(0.20 \mathrm{~g})$ were added every $30 \mathrm{~min}$. Captions to the Tables and Figures indicate how other conditions were changed.

The reaction course was followed by gas-chromatography. Conversion factors were calculated by the internal standard.

Competitive Reactions (Fig. 4).--In an Erlenmeyer flask $\left(20 \mathrm{~cm}^{3}\right)$ thermostatted at $50 \pm 0.1^{\circ} \mathrm{C}$, a mixture of isooctane solutions $\left(0.07 \mathrm{~mol} \mathrm{dm}^{-3} ; 7.0 \mathrm{~cm}^{3}\right)$ of $\mathrm{PhF}, \mathrm{PhCl}, \mathrm{PhBr}$ and $\mathrm{PhI}$ $(0.5 \mathrm{mmol}$ of each) containing $\mathrm{n}$-dodecane $(0.05 \mathrm{~g})$ as internal standard, $50 \%$ aqueous $\mathrm{KOH}\left(4.0 \mathrm{~cm}^{3}\right), 5 \% \mathrm{Pd} / \mathrm{C}(0.032 \mathrm{~g}$, $0.015 \mathrm{mmol}$ of $\mathrm{Pd})$ and Aliquat $336(0.085 \mathrm{~g}, 0.20 \mathrm{mmol})$ were magnetically stirred at ca. $1000 \mathrm{rpm}$; of $\mathrm{NaH}_{2} \mathrm{PO}_{2} \cdot \mathrm{H}_{2} \mathrm{O}$ $(0.20 \mathrm{~g}, 1.9 \mathrm{mmol})$ was added every $30 \mathrm{~min}$. Analyses were performed as previously reported.

Reduction of 1,2,4-Trichlorobenzene, 1,4- and 1,2-Dichlorobenzene and Chlorobenzene (Table 6). - The conditions used for the reduction of TeCB were also similarly used for TCB, orthoand para-DCB and $\mathrm{PhCl}$. Starting with isooctane solutions $\left(0.07 \mathrm{mmol} \mathrm{dm} \mathrm{dm}^{-3} ; 7.0 \mathrm{~cm}^{3}\right)$ of the corresponding aryl chlorides and $\mathrm{n}$-dodecane as the internal standard, the reactions were carried out with $50 \%$ aqueous $\mathrm{KOH}\left(4.0 \mathrm{~cm}^{3}\right), 5 \% \mathrm{Pd} / \mathrm{C}$ $(0.032 \mathrm{~g}, 0.015 \mathrm{mmol}$ of Pd) and Aliquat $336(0.085 \mathrm{~g})$. The reaction mixtures were magnetically stirred at $c a .1000 \mathrm{rpm}$, $\mathrm{NaH}_{2} \mathrm{PO}_{2} \cdot \mathrm{H}_{2} \mathrm{O}(0.20 \mathrm{~g}, 1.9 \mathrm{mmol})$ being added every $30 \mathrm{~min}$.
Reactions were followed by gas-chromatography; conversions were determined by comparison to the internal standard.

Dehalogenation of Chlorobenzenes, Bromobenzenes and their p-Methoxy Derivatives (Table 7).-With isooctane solutions $\left(0.07 \mathrm{~mol} \mathrm{dm}^{-3}, 7.0 \mathrm{~cm}^{3}\right)$ of the corresponding aryl halides and n-dodecane as the internal standard, the reactions were carried out in $50 \%$ aqueous $\mathrm{KOH}\left(4.0 \mathrm{~cm}^{3}\right)$ with $5 \% \mathrm{Pd} / \mathrm{C}(0.032 \mathrm{~g}$, $0.015 \mathrm{mmol}$ of Pd) and Aliquat $336(0.085 \mathrm{~g})$; the mixtures were magnetically stirred at $c a .1000 \mathrm{rpm}, \mathrm{NaH}_{2} \mathrm{PO}_{2} \cdot \mathrm{H}_{2} \mathrm{O}(0.20 \mathrm{~g}, 1.9$ $\mathrm{mmol}$ ) being added every $30 \mathrm{~min}$. Analyses were carried out by gas chromatography.

\section{Acknowledgements}

This work was supported by Ministero Università e Ricerca Scientifica e Tecnologica, fondo $40 \%$.

\section{References}

1 (a) P. N. Rylander, Catalytic Hydrogenolysis in Organic Synthesis, Academic Press, New York, 1973, pp. 235-248; (b) A. R. Pinder, Synthesis, 1980, 425.

2 (a) P. Dini, J. C. J. Bart and N. Giordano, J. Chem. Soc., Perkin Trans. 2, 1975, 1479; (b) P. N. Pandey and M. L. Purkayastha, Synthesis, 1982, 866.

3 J. Käsbauer, H. Fiege, H. Schmidt and K. Wedemeyer, Europ. Pat. 0301 343, 1988.

4 A. Akagh, J. C. Poite and M. Chanon, Org. Prep. Proc. Int., 1985, $17,219$.

5 (a) S. K. Boyer, J. Bach, J. McKenna and E. Wedemeyer, J. Org. Chem., 1985, 50, 3408; (b) S. K. Boyer, U.S. Pat. 4,618,686, 1986 (Chem. Abstr., 1989, 110, 212329); (c) S. K. Boyer, J. McKenna, J. Karliner and M. Nirsberger, Tetrahedron Lett., 1985, 26, 3677; (d) G. V. Bakulina and B. V. Erofeev, Zh. Fiz. Khim., 1972, 46, 211 (Chem. Abstr., 1972, 76, 140121); (e) O. A. Karpeiskaya, A. A. Belyi, M. E. Vol'pin, Izv. Akad. Nauk SSSR (Khim), USSR, 1985, 34, 1554; (f) A. F. Brigas and R. A. W. Johnstone, Tetrahedron Lett., 1990, 31, 5789; (g) C. M. Hu and M. H. Tu, J. Fluorine Chem., 1991, 55, 101; (h) B. T. Khai and A. Arcelli, J. Org. Chem., 1989, 54, 949.

6 H. Wiener, H. Blum and Y. Sasson, J. Org. Chem., 1991, 56, 6145.

7 (a) M. K. Anwer and A. F. Spatola, Tetrahedron Lett., 1975, 26, 1381; (b) A. J. de Koning, Org. Prep. Proc. Int., 1975, 7, 31.

8 (a) C. Starks and C. Liotta, Phase Transfer Catalysis, Academic Press, New York, 1978; (b) E. V. Dehlow and S. S. Dehmlow', Phase Transfer Catalysis, 2nd edn., Verlag Chemie, Weinheim, 1983; (c) P. Tundo, Continuous Flow Methods in Organic Synthesis, Ellis Horwood, Chichester, 1991, ch. 4.

9 (a) T. Imamoto, T. Takeyama and T. Kusumoto, Chem. Lett., 1985, 1491; (b) C. Carfagna, A. Musco and R. Pontellini, J. Mol. Catal., 1989, 57, 23.

10 I. Pri-Bar and O. Buchman, J. Org. Chem., 1986, 51, 734.

11 B. Coq, G. Ferrat and F. Figueraz, J. Catal., 1986, 101, 434.

Paper 2/05000E

Received 17th September 1992 Accepted 13th November 1992 